\title{
Roadmap for Ross procedure: Staged strategy
}

\author{
Viktor Hraska, MD, PhD, Michael E. Mitchell, MD, and Ronald K. Woods, MD, PhD
}

\begin{abstract}
Feature Editor's Introduction-Although remarkable progress has been made during the last decade to achieve a durable aortic valve $(A V)$ repair in children, $A V$ replacement in children is sometimes required. The Ross procedure remains the operation of choice for $A V$ replacement in children. It appears beneficial to postpone Ross procedure beyond infancy, whenever possible, and, ideally, until adolescence or adulthood, when somatic growth has been completed. In this issue of the Journal, the team of experts with extensive experience in AV surgery share their views on the strategy that may optimize the outcomes after Ross procedure in children.
\end{abstract}

\section{Igor E. Konstantinov, MD, PhD, FRACS}

Buratto and colleagues ${ }^{1}$ deserve our appreciation for the outcomes and careful longer-term follow-up of a large cohort of pediatric patients with aortic valve (AV) disease undergoing a primary Ross procedure or a Ross procedure as a secondary surgery after initial AV repair. Their data represent many years of experience from a high-volume institution with highly developed expertise in pediatric AV surgery. The cohort included 140 patients spanning the interval from 1995 to 2018 . Of 140 Ross procedures, $51.4 \%$ were primary operations and $48.6 \%$ were secondary operations. There were no significant differences in survival or freedom from reoperation in the unmatched cohort. However in a propensity-matched cohort of 50 patients, survival at 10 years was $90.0 \%$ in the primary Ross group compared with $96.8 \%$ in the secondary Ross group $(P=.04)$. The same trend was seen in freedom from autograft reoperation at 10 years of $82 \%$ in the primary Ross group compared with $97.0 \%$ in the secondary Ross group $(P=.03)$. In a thoughtful and tempered discussion of their data, the authors concluded that a strategy of initial AV repair followed by a delayed or secondary Ross procedure may provide better long-term survival and freedom from autograft reoperation. The "adult cardiac surgeon" perspective in the accompanying editorial by ElHamamsy and colleagues ${ }^{2}$ lends support to this strategy

\footnotetext{
From the Division of Pediatric Cardiothoracic Surgery, Herma Heart Institute at Children's Wisconsin, Department of Surgery, Medical College of Wisconsin, Milwaukee, Wis.

Received for publication Nov 19, 2020; revisions received Dec 15, 2020; accepted for publication Dec 17, 2020; available ahead of print Jan 13, 2021.

Address for reprints: Viktor Hraska, MD, PhD, Division of Pediatric Cardiothoracic Surgery, Herma Heart Institute, Children's Wisconsin, Department of Surgery, Medical College of Wisconsin, $9000 \mathrm{~W}$ Wisconsin Ave, B730, Milwaukee, WI 53226 (E-mail: vhraska@chw.org)

J Thorac Cardiovasc Surg 2022;163:379-82

$0022-5223 / \$ 36.00$

Copyright (c) 2021 by The American Association for Thoracic Surgery https://doi.org/10.1016/j.jtcvs.2020.12.141
}

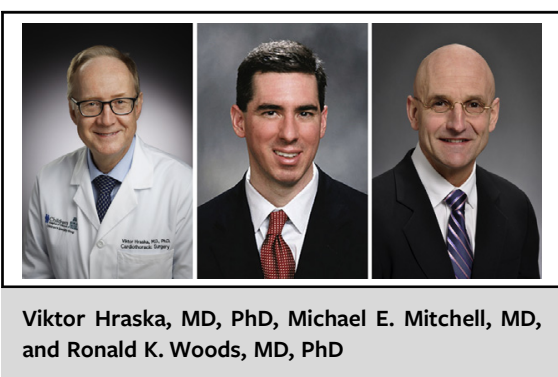

\begin{abstract}
CENTRAL MESSAGE
When feasible in young children, we advocate for initial AV repair. Deferring the Ross procedure may enhance autograft durability and will certainly delay the clock on pulmonary conduit reinterventions.
\end{abstract}

This Invited Expert Opinion provides a perspective on the following paper: J Am Coll Cardiol. 2020 Sep 29;76(13):1564-1573. https://doi.org/10 1016/j.jacc.2020.07.058

See Commentaries on pages 383 and 385 .

for appropriately selected adult patients as well. For patients who should not take anticoagulation or choose to avoid it, they propose a nonthrombogenic AV surgery algorithm contingent upon the feasibility of repair, availability of surgical expertise with the Ross procedure, and use of tissue valves as a Ross deferment option. We respectfully acknowledge this specific adult cardiac perspective, but will limit our focus to predominantly the younger pediatric population.

Variations in specific patient characteristics, institutional treatment strategies, surgical expertise and surgical procedures, and the lack of lifelong comparative followup data truly challenge objective decision making in this cohort of patients. So, the conversations continue regarding balloon versus knife, the advantages of repair versus concerns about material-related durability, and Ross now versus later. ${ }^{3-6}$ We tend to agree with Buratto and colleagues ${ }^{1}$ despite the fact they analyzed only reintervention and not echocardiographic data. The threshold for reintervention could vary depending on the number of prior sternotomies. Before offering an opinion on explanations for why such findings might be true, we will first 
offer a general opinion regarding the initial repair as a preface to the secondary Ross.

\section{NEONATAL AND INFANT AORTIC STENOSIS: BALLOON VERSUS SURGERY}

Very simply, we believe that surgery is the best option..$^{6-8}$ Surgery is controlled under direct vision and permits treatment of both the commissures and leaflets. Balloon valvotomy is effectively blind and can only relieve stenosis by tearing something, typically the thinnest most pliable portion of a leaflet, which is often a leaflet that would be useful to retain for repair. In contrast to the result with surgery, this uncontrolled tear, even if it does not result in significant early aortic regurgitation, produces a valve substrate that is far less amenable to additional repair in the future. The good leaflet material has been torn and will become dysplastic, typically requiring replacement or significant patch augmentation. Although failure after surgery is predominantly stenosis, failure after balloon is typically regurgitation. We prefer the physiology of stenosis and some degree of left ventricular (LV) hypertrophy rather than a dilated LV and potentially aortic annulus. The former is certainly the preferred substrate for the Ross procedure. ${ }^{4}$

Durability of initial repair varies with valve substrate. In particular, valves with 3 commissures (although less common in neonatal aortic stenosis) demonstrate excellent long-term function and freedom from replacement. Compared with balloon valvotomy, repair of even unicuspid valves provides greater freedom from reintervention early in life. ${ }^{6,8}$ Also, surgery rarely results in acute severe aortic regurgitation necessitating a high-risk salvage Ross procedure. Nevertheless, repair is usually a temporizing solution primarily aimed at preserving the native valve as long as possible, without affecting LV function, and leaving all other, more durable options still valid and without limitations.

\section{NEONATAL AND INFANT AORTIC STENOSIS: WHO SHOULD GET THE BIG OPERATION UP FRONT}

There is a subgroup of neonates and infants who benefit from a primary Ross-Konno operation.

Congenital aortic stenosis is not always a separate morphological lesion, but rather a spectrum of conditions including different degrees of hypoplasia of the left heart structures from the mitral valve to the aortic arch. ${ }^{9}$ Judgment regarding suitability for biventricular repair is far from perfect, but in patients clearly deemed candidates for biventricular repair, efforts to defer the Ross-Konno with multiple surgical or interventional palliations may lead to progression of left-sided disease: worsening of endocardial fibroelastosis and diastolic dysfunction; further impairment of papillary muscle mobility and mitral valve function; and left atrial hypertension leading to progressive pulmonary vascular hypertension. ${ }^{10}$

In this age group, the pulmonary autograft represents an inherently properly sized AV replacement for a small aortic annulus. The ventricular septal incision alleviates all levels of outflow stenosis and allows easy access to the LV cavity and effective resection of endocardial fibroelastosis. An overall freedom from reintervention and reoperation of the LV outflow tract being close to $100 \%$ at midterm follow-up is evidence of proportional somatic growth of the autograft and its capability to adapt to systemic pressure conditions. ${ }^{10}$

We acknowledge the relatively high early mortalities of a neonatal or infant Ross-Konno reported in several series. ${ }^{10-12}$ Associated lesions, particularly the mitral valve and aortic arch, and the specific approaches and timing with which these are addressed likely account for much of this risk. The reality is that devising and executing an optimal surgical strategy can be challenging. Therefore, in our opinion, such patients should be referred to a center with established expertise and experience. Early survival notwithstanding, a clear disadvantage of the Ross-Konno in these young patients is the relatively high rate of reintervention on the right ventricular outflow tract, inherent to pulmonary valve replacement in any young patient. ${ }^{11}$

\section{REPAIR BEYOND INFANCY}

The older pediatric patient can present with stenosis, regurgitation, or often both. Although repair is safe and effective in delaying the need for replacement, patient growth and attrition of any patch material used in the reconstruction limit durability, typically to less than 10 years. $^{4-6,13,14}$ There are numerous reports of various techniques of repair to address all levels of the AV complex. We will not elaborate on further detail but will comment on general principles. A nonrestrictive tricuspid repair with native tissue and an annulus and sinotubular junction that can grow to an appropriate size offer excellent freedom from recurrent stenosis or regurgitation. This effect may be due to a better geometric configuration leading to a more favorable hemodynamic profile that then positively affects durability. ${ }^{5,6}$ Another advantage is that a tricuspid geometry favors further possibility of re-repair if LV function is preserved (personal observation). It is generally accepted that the benefits of keeping the compliance of the native aortic root outweighs the risk of exposing the patients to a higher rate of reoperation. In older children, tricuspidization has a durability similar to that of repaired bicuspid valves. ${ }^{5}$ Restrictive procedures that use patch material or permanently restrict the annulus or sinotubular junction fare less well, particularly in younger children.

Although certain patch materials, whether as cusp extension or leaflet replacement, may demonstrate better early performance, all patch material developed thus far have a 
common fate: degeneration with fibrosis and retraction. Calcification is frequently seen at the stress-related junction between native leaflet and patch material. In addition, suture lines are required to flex repeatedly and repair forces are commonly concentrated into small regions, resulting in structural failure. In theory, such failure might be mitigated by distributing the force line more uniformly around the leaflet or annulus. The Ozaki technique of complete valve replacement distributes the suture line forces over a larger area. ${ }^{4,15}$ Because the free edge length of the leaflets are nearly twice the intercommissural distance, this technique could in theory both accommodate intercommissural expansion and limit leaflet stress due to abundant coaptation height. Both would yield the desired result of increased durability and accommodation of growth. Ozaki and colleagues ${ }^{16}$ results in older patients are encouraging. Results limited to short-term follow-up in children or teenagers are reasonably good, but we should temper our expectations. ${ }^{17,18}$ A Konno root enlargement to accommodate upsized templates adds complexity ${ }^{18}$; moreover, subsequent patch calcification and scarring around the root could negatively affect future replacement options. Replacement of only the diseased cusp and preservation of more native tissue may be a more physiologic solution for a growing child with no untoward impact on future replacement options. ${ }^{19}$ Regardless of approach, material limitations will inevitably dictate outcome.

We believe 3-dimensional echocardiography offers important insight into valve morphology, particularly the presence and height of commissures and leaflet coaptation height. This knowledge permits a better informed repair strategy based on the most well-developed commissure and sites for realignment of the other commissures. It also provides better insight into neonatal valve morphology, leaflet height, and how extensive a commissurotomy should be and the number of true commissures, and therefore the likelihood of a more durable repair. ${ }^{8}$

\section{ROSS PROCEDURE}

The Ross procedure is clearly our most attractive valve replacement option in children. Long-term follow-up has demonstrated excellent survival and LV health. The subsequent need for pulmonary valve replacement aside, longerterm follow-up has also proven that the Ross is not necessarily a lifelong cure because autograft failure occurs in $10 \%$ to $20 \%$ of patients at 10 to 15 years of followup. ${ }^{20,21}$ In fact, we are not aware of any large pediatric series with more than 25 years of follow-up on all patients. But we do know the characteristics of any alternative pathway, so the Ross remains a cornerstone, ${ }^{22}$ with further efforts focused on preventing autograft failure. Depending on the patient's age and growth status, both temporary or permanent restriction of the sinotubular junction or annulus are reasonable options with encouraging results. ${ }^{23}$ The supported Ross (inside a Dacron conduit) should theoretically address all levels of potential dilation. Short- to intermediate-term data are encouraging; longer-term data are currently not available. ${ }^{24}$ We do believe the native left ventricular outflow tract offers important support, and when feasible, the autograft should be seated low to take advantage of this support. In the younger, growing patient, temporary stabilization of the sinotubular junction with a resorbable suture seems harmless. Stabilization during the first few weeks of autograft accommodation might offer important, longer-term payoff..$^{25}$ But is there some other strategy that could prolong autograft life? This brings us full circle back to the issue raised by Buratto and colleagues. $^{1}$

\section{IF A SECONDARY ROSS PROLONGS THE FUNCTION OF THE AUTOGRAFT, HOW, WHY, WHAT MECHANISM?}

The explanation provided by the authors is based on some degree of external scar and fibrosis that ameliorate any dilation that might have otherwise been worse in a primary Ross. Let's examine this unproven hypothesis. Suppose it is 8 years after an initial commissurotomy and leaflet thinning during which some dissection occurred around the aorta (for the clamp), no sutures were placed in the annulus, there would be an aortic suture line, and then general postoperative inflammation and healing. The child now has a relatively normal-size annulus and sinotubular junction, of the pulmonary valve as well, so structures have grown commensurately. It is difficult to explain why the pulmonary valve would grow normally in a low-pressure system and then somehow be supported by this "protective" fibrosis in a high-pressure system. Is it change in the compliance of the native aortic annulus or ascending aorta at the suture line that have grown up to now? Or is it the number of sternotomies and mediastinal dissections and more so what occurs in the mediastinum right after the secondary Ross, rather than the condition of the mediastinum before the secondary Ross? In other words, could it be that the early postoperative mediastinal inflammatory process in a redo setting results in a more protective fibrotic healing process? Another possibility is that with a secondary Ross, the harvested muscle cuff might be shorter, necessitating sutures being placed more near the true, partially fibrotic pulmonary annulus rather than the muscle cuff (which dies). A final unexplored hypothesis is that the inflammatory process of the initial surgery enhances an adventitial neovasculature that might help provide better microvascular support to the pulmonary wall compared with an otherwise devascularized autograft dependent on luminal imbibition. We do not presume to know the answer. Had the authors provided some data about diameters and valve function, we might be better informed. Of course, we cannot dismiss the limitations of propensity matching of a limited set of variables and the possibility 
of this observation being a mere analytic artifact. We doubt it, but it remains on the list of possibilities. Nevertheless, we are grateful to the authors because they have provided us thought-provoking data and insight and yet potentially another strategy to enhance the life of the autograft.

\section{CONCLUSIONS}

Regardless of whether or not a secondary Ross "protects" the autograft, we completely agree with the authors that we should, when feasible, perform an initial repair with a focus on maintaining the health of the LV and preserving all other options for a subsequent intervention. At the least, this delays starting the clock on the durability of a right ventricle to pulmonary conduit in a young child and increases the durability if placed at a larger diameter in an older child.

\section{Conflict of Interest Statement}

The authors reported no conflicts of interest.

The Journal policy requires editors and reviewers to disclose conflicts of interest and to decline handling or reviewing manuscripts for which they may have a conflict of interest. The editors and reviewers of this article have no conflicts of interest.

\section{References}

1. Buratto E, Wallace FRO, Fricke TA, Brink J, d'Udekem Y, Brizard CP, et al. Ross procedures in children with previous aortic valve surgery. J Am Coll Cardiol. 2020;76:1564-73.

2. El-Hamamsy I, Stelzer P, Adams DH. The Ross procedure in children undergoing reintervention. Another victory for nonthrombogenic surgery. J Am Coll Cardiol. 2020;76:1574-6.

3. Wilder TJ, Caldarone CA, Van Arsdell GS, Pham-Hung E, Gritti M, Al Jughiman M, et al. Aortic valve repair for insufficiency in older children offers unpredictable durability that may not be advantageous over a primary Ross operation. Eur J Cardiothorac Surg. 2016;49:883-92.

4. D’Udekem Y, Tweddell JS, Karl TR. The great debate series: surgical treatment of aortic valve abnormalities in children. Eur J Cardiothorac Surg. 2018;53:1-13.

5. Vergnat M, Asfour B, Arenz C, Suchowerskyj P, Bierbach B, Schindler E, et al. Contemporary results of aortic valve repair for congenital disease: lessons for management and staged strategy. Eur J Cardiothorac Surg. 2017;52:581-7.

6. Vergnat M, Asfour B, Arenz C, Suchowerskyj P, Bierbach B, Schindler E, et al. Aortic stenosis of the neonate: a single-center experience. J Thorac Cardiovasc Surg. 2019;157:318-26.e1.

7. Siddiqui J, Brizard CP, Galati JC, Iyengar A, Hutchinson D, Konstantinov I, et al. Surgical valvotomy and repair for neonatal and infant congenital aortic stenosis achieves better results than interventional catheterization. J Am Coll Cardiol. 2013;62:2134-40.

8. Hraska V. Neonatal aortic stenosis is a surgical disease. Semin Thorac Cardiovasc Surg Pediatr Card Surg Annu. 2016;19:2-5.
9. Spicer DE, Hraska V, Anderson RH, Ginde S, Block JR. Congenital anomalies of the aortic valve and left ventricular outflow tract. In: Wernovsky G, ed. Anderson's Pediatric Cardiology. 4th ed. Philadelphia, PA: Elsevier; 2020:820-42.

10. Aszyk P, Thiel C, Sinzobahamvya N, Luetter S, Photiadis J, Haun C, et al. RossKonno procedure in infants: mid-term results. Eur J Cardiothorac Surg. 2012;42: 687-94.

11. Brown JW, Ruzmetov M, Vijay P, Rodefeld MD, Turrentine MW. The RossKonno procedure in children: outcomes, autograft and allograft function, and reoperations. Ann Thorac Surg. 2006;82:1301-6.

12. Ohye RG, Gomez CA, Ohye BJ, Goldberg CS, Bove EL. The Ross/Konno procedure in neonates and infants: intermediate-term survival and autograft function. Ann Thorac Surg. 2001;72:823-30.

13. d'Udekem Y, Siddiqui J, Seaman CS, Konstantinov IE, Galati JC, Cheung MM, et al. Long-term results of a strategy of aortic valve repair in the pediatric population. J Thorac Cardiovasc Surg. 2013;145:461-9.

14. Polimenakos AC, Sathanandam S, Elzein C, Barth MJ, Higgins RS, Ilbawi MN Aortic cusp extension valvuloplasty with or without tricuspidization in children and adolescents: long-term results and freedom from aortic valve replacement. $J$ Thorac Cardiovasc Surg. 2010;139:933-41.

15. Tweddell JS. Are complex aortic valve repairs a real alternative to replacement in children? Eur J Cardiothorac Surg. 2017;52:588-9.

16. Ozaki S, Kawase I, Yamashita H, Uchida S, Takatoh M, Kiyohara N Midterm outcomes after aortic valve neocuspidization with glutaraldehyde treated autologous pericardium. J Thorac Cardiovasc Surg. 2018;155: 2379-87.

17. Wiggins LM, Mimic B, Issitt R, Ilic S, Bonello B, Marek J, et al. The utility of aortic valve leaflet reconstruction techniques in children and young adults. J Thorac Cardiovasc Surg. 2020;159:2369-78.

18. Baird CW, Sefton B, Chavez M, Sleeper LA, Marx GR, del Nido PJ. Congenital aortic and truncal valve reconstruction utilizing the Ozaki technique: short-term clinical results. J Thorac Cardiovasc Surg. February 18, 2020 [Epub ahead of print].

19. Konstantinov IE, Naimo PS, Buratto E. Commentary: Ozaki valve reconstruction in children: is it still a valve replacement? J Thorac Cardiovasc Surg. February 14, 2020 [Epub ahead of print].

20. Charitos EI, Takkenberg JJ, Hanke T, Gorski A, Botha C, Franke U, et al. Reoperations on the pulmonary autograft and pulmonary homograft after the Ross procedure: an update on the German Dutch Ross registry. J Thorac Cardiovasc Surg. 2012;144:813-23.

21. Takkenberg JJ, Klieverik LM, Schoof PH, van Sulyen RJ, van Herwerden LA, Zondervan PE, et al. The Ross procedure: a systematic review and meta-analysis. Circulation. 2009;119:222-8.

22. Elkins RC, Lane NM, McCue C. Ross operation in children: late results. J Heart Valve Dis. 2001;10:736-41.

23. Brown JW, Ruzmetov M, Shahriari AP. Modification of the Ross aortic valve replacement to prevent late autograft dilatation. Eur J Cardiothorac Surg. 2010;37:1002-7.

24. Jacobsen RM, Earing MG, Hill GD, Barnes M, Mitchell ME, Woods RK, et al. The externally supported Ross operation: early outcomes and intermediate follow-up. Ann Thorac Surg. 2015;100:631-8.

25. Skillington PD, Mokhles MM, Takkenberg JJ, Larobina M, O'Keefe M, Wynne R, et al. The Ross procedure using autologous support of the pulmonary autograft: techniques and late results. J Thorac Cardiovasc Surg. 2015;149: S46-52.

Key Words: congenital aortic stenosis, Ross procedure, aortic valvuloplasty, complex aortic valve reconstruction 